\title{
Analysis of Data from Software Sensor for Smart Airbags Deployment
}

\author{
EISayed A EINashar ${ }^{1 *}$ and Zlatin Zlatev ${ }^{2}$
}

${ }^{1}$ Faculty of Specific Education, Kafrelsheikh University, Egypt

${ }^{2}$ Faculty of Technics and Technologies, Trakia University, Bulgaria

\begin{abstract}
The report represents the peculiarities of using intelligent airbags in cars. A review is made of the sensors used to activate the airbag system in terms of their advantages and disadvantages. Presented are software applications using the capabilities of the hardware of sensor devices in order to build a common signal. Based on a study of literature is developed a software sensor for airbag deployment depending on the object on passenger seat. The work of this sensor is studied in case of interrupted any of the input signals. The results show that by combining data from three hardware sensors is received error up to $5 \%$ in distinguish between the objects on the passenger seat of the car. The dropping of the signal in hardware sensors affects the accuracy of i dentifying the object on the passenger seat.
\end{abstract}

Keywords: Automotive active safety; Smart airbags; Software sensor

\section{Introduction}

The technology of application of airbags has proven successful over time as compared to other ways of ensuring safety in vehicles as headrests and seatbelts. The older models airbags, but also some new and intelligent ones also can cause injuries in children and adults people. The combination of side and front airbags significantly reduce the risk in an accident [1] but these safety systems are not universal. This suggests the use of specific airbag systems associated with the materials of which are made, their location in the vehicle interior, systems for their operation associated with sensor technology and actuators included in this area. The systems for activation of the airbags are not so sophisticated, they can be activated at wrong moment. For example, weight sensors are activated by the pressure exercised by the passenger, when he sits on the seat. In this case, the airbag is activated in an accident. If on the passenger seat is placed capacious object with greater weight it will also lead to activation of the airbag [2].

Most of the developments related to airbags are related to safety of the driver and front passenger, and those in the back seat against the direction of movement of the car. $40 \%$ of collisions and $30 \%$ of the causes of injury to passengers are in a side collision $[1,3,4]$.

In the literature [5-7] states that the development of side airbags is much harder than front it depends of textile materials, sensors used and time for deployment. Much of the energy in a frontal collision is absorbed by the bumper, the bonnet and the engine, the reaching blow wave to the driver and passengers going for $30-40 \mathrm{~ms}$. In a side blow the time to reach blow wave is 5-6 ms as the only barrier is the door of the car. These times are critical in the development of systems for control of airbags.

The aim of this report is a comparative analysis of sensors used to activate the airbags in terms of their advantages and disadvantages and to analyze a software sensor for activation of airbags for active safety in the car.

\section{Exposure}

Using intelligent airbag systems improves the sensing functions and control options for the airbag inflation process. Such improvement functions are [1]:
$>$ Impact severity detection through improvement of triggering algorithm;

$>$ Seat belt usage detection;

$>$ Occupant presence, position and weight;

$>$ Seat position and back rest inclination detection;

$>$ Introduction of up to ten and more different triggering thresholds;

$>$ Depowered airbag: it use reduced gas inflator power, which leads to a reduced inflation speed, inflation severity and risk to occupants.

The application of sensors and actuators for activation of air bags must meet certain restrictions [2,5]: a small amount of equipment including airbag control system; reducing the cost of production and installation; improve safety; enhancing ergonomics.

Different types of sensors measuring wheel speed, seat occupant status, brake pressure and impact, and other vehicle status indicators are monitored by the airbag control unit located in the front portion of the cabin. The sensors relay signals to the airbag control unit, which analyzes the data and can control safety features like seat belt lock, automatic door locks, as well as airbag deployment. The advantages and disadvantages of airbag deployment sensors are described in Table 1.

The choice for suitable sensors for smart airbag application has to be taken in consideration of the following criteria [3]: System cost; Bandwidth; Latency; Determinism; Safety; Recovery actions; Physical layer.

*Corresponding author: EISayed A EINashar, Faculty of Specific Education Kafrelsheikh University, Kafr El Sheikh Egypt El-Geish Street, 33516 Kafr E Sheikh, Egypt, Tel: 20473214998; E-mail: smartex@kfs.edu.eg

Received December 01, 2017; Accepted December 28, 2017 ; Published January 05, 2018

Citation: EINashar EA, Zlatev Z (2018) Analysis of Data from Software Sensor for Smart Airbags Deployment. Adv Robot Autom 7: 181. doi: 10.4172/21689695.1000181

Copyright: (c) 2018 EINashar EA, et al. This is an open-access article distributed under the terms of the Creative Commons Attribution License, which permits unrestricted use, distribution, and reproduction in any medium, provided the original author and source are credited. 
Citation: EINashar EA, Zlatev Z (2018) Analysis of Data from Software Sensor for Smart Airbags Deployment. Adv Robot Autom 7: 181. doi: 10.4172/2168-9695.1000181

Page 2 of 6

\begin{tabular}{|c|c|c|c|}
\hline Sensor & Advantages & Disadvantages & Reference \\
\hline Accelerometer & $\begin{array}{l}\text { Simple design, easy to use, using different } \\
\text { principles of action - capacitive tenzo-, piezo, mechanical }\end{array}$ & Large shifts deadweight may lead to nonlinearity of the output signal & [1] \\
\hline Capacitive & $\begin{array}{l}\text { A large output signal and a good sensitivity, due to the low } \\
\text { noise characteristics }\end{array}$ & $\begin{array}{l}\text { Influence of surrounding electro- magnetic fields, which requires } \\
\text { careful shielding; Parasitic capacitance at the input of interface } \\
\text { amplifiers }\end{array}$ & {$[17]$} \\
\hline Ultrasonic & $\begin{array}{l}\text { Independence of the optical properties of the object; Linear } \\
\text { relationship between the output signal and the measured } \\
\text { distance. }\end{array}$ & $\begin{array}{l}\text { Need appropriate surface of the object and its location relative to the } \\
\text { sensor; Relatively high response time; Depending of a the reading } \\
\text { from air condition }\end{array}$ & {$[13]$} \\
\hline Infrared & Widely available, enough information about their use & $\begin{array}{l}\text { Probability of false alarms due to heat flow - air conditioning, solar } \\
\text { heating. }\end{array}$ & [13] \\
\hline Temperature & $\begin{array}{l}\text { Continuous temperature monitoring; easy } \\
\text { installation and maintenance }\end{array}$ & Linear and non-linear part of characteristic & [13] \\
\hline Video camera & $\begin{array}{l}\text { Separation of the object from background easily recognize } \\
\text { the position of the head and body }\end{array}$ & $\begin{array}{l}\text { Need larger computational resources, and a longer time for data } \\
\text { processing }\end{array}$ & {$[3,18]$} \\
\hline Stereo camera & The object is recognized in depth & $\begin{array}{l}\text { Need larger computational resources, and a longer time for data } \\
\text { processing }\end{array}$ & [4] \\
\hline Infrared camera & $\begin{array}{l}\text { Easily distinguish passengers from luggage, determining the } \\
\text { position of the head and body; Less affected by sunlight } \\
\text { and fog }\end{array}$ & $\begin{array}{l}\text { Does not distinguish human from the background at the same } \\
\text { temperature; High cost of equipment. }\end{array}$ & [13] \\
\hline Weight & Easy to use, quick response & $\begin{array}{l}\text { Non-linearity of the output characteristic; It can be activated when a } \\
\text { heavy object is on seat }\end{array}$ & [6] \\
\hline Micro switch & Easy to use, quick response & $\begin{array}{l}\text { Two states of outputs (on/ off); It can be activated when a heavy } \\
\text { object is on seat }\end{array}$ & [2] \\
\hline
\end{tabular}

Table 1: Advantages and disadvantages of the sensors used to activate the intelligent airbags.

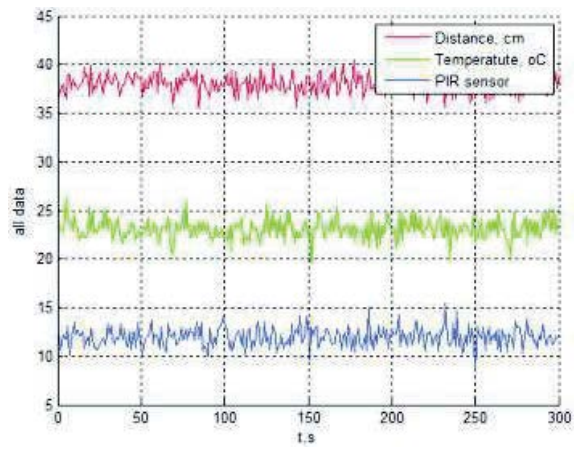

7 years old child

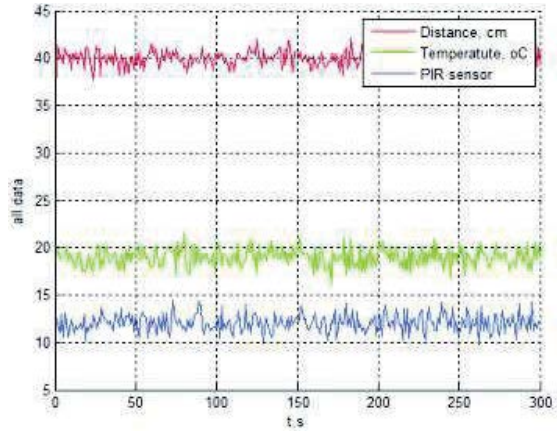

22 years old man

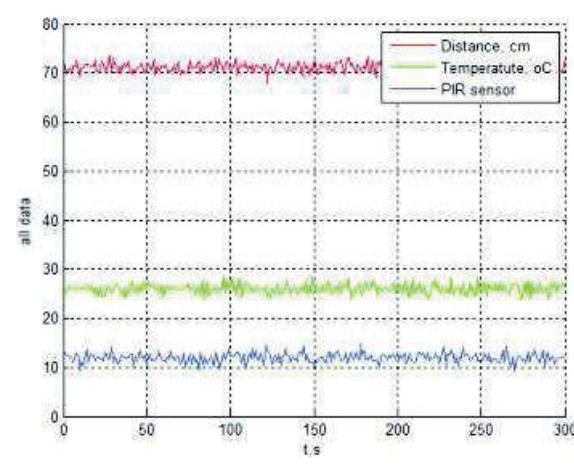

Dog laying

Figure 1: Examples of signals of three sensors.

Systems using video sensor have proven over the years as successful in identifying persons determining the position of the body and the head of the driver or passenger, which is proven by numerous studies [8-12]. Despite the fact that systems using video sensor have proven their advantages in the study of triggering systems, they are not adopted by the automotive industry [13]. One of the reasons is that many consumers do not want to be photographed by cameras.

In recent years there has been entering in mobile devices, industrial automation, software-based sensors that are not technically feasible, but actually retrieve data from one or more hardware-based sensors and based on their values made its own result [14]. Interesting problem in the operation of the sensors is the reconciliation of data derived from multiple hardware sources, in which can be generated synthetic indications of new characteristics. A typical example of such a combination is the result of the data, those which develop the software sensors.

\section{Material and Methods}

Data from [13] is used, where the author analyzes the work of developed by him activation system for intelligent airbag. The system consists of three sensors - ultrasonic for distance, temperature and passive infrared sensor PIR. The author is investigated raw data from the three sensors for objects on passenger seat-Empty seat, 1 year old child, 2 years old child, 7 years old child, 13 years old child, 22 years old man, Box, Dog laying.

Examples of the operation of the the three sensors are presented in Figure 1.

In this study the data were processed with Kalman filter [15] Combining of the data is done through a central limit theorem [16] and Fraser-Potter fixed-interval smoother [17,18].

The output signal $\mathrm{y}_{\mathrm{c}}$ and its dispersion $\sigma \mathrm{c}$ is calculated by:

$$
\begin{aligned}
& y_{c}=\sigma_{c}^{2}\left(\sigma_{1}^{-2} x_{1}+\sigma_{2}^{-2} x_{2}+\sigma_{3}^{-2} x_{3}\right) \\
& \sigma_{c}^{2}=\left(\sigma_{1}^{-2}+\sigma_{2}^{-2}+\sigma_{3}^{-2}\right)^{-1}
\end{aligned}
$$

where $\mathrm{X}_{1}, \mathrm{X}_{2}$ and $\mathrm{X}_{3}$ simultaneously measured signals with their dispersions $\sigma 1, \sigma 2$ and $\sigma 3$. 
Citation: EINashar EA, Zlatev Z (2018) Analysis of Data from Software Sensor for Smart Airbags Deployment. Adv Robot Autom 7: 181. doi: $10.4172 / 2168-9695.1000181$

Page 3 of 6

The results are processed with discriminant classifier using nonlinear separating function. The classification is evaluated by common error of classification.

In the combining of the data from sensors may be obtained falling or improper reading of the one of the sensors. In the study [13], such are the ultrasonic and temperature sensors, whose signals vary widely or entirely eliminated depending on the object standing on the passenger seat.

\section{Results and Discussion}

Based on the literature study and requirements for building software sensors [19-21] is proposed solution to a software sensor. In Figure 2 is a block diagram of the developed software sensor. The signals from the three sensors are precisely filtered with Kalman Filter.

The filtered signals are fed to a program block for combining, the output of which gives the total signal.
The results of the software sensor that combine signals from three sensors-ultrasonic, PIR and temperature are presented in Figure 3. A visible difference is observed between the signals of the software sensor depending on the object on the vehicle seat.

In Figure 4 are examples of separability between objects on the passenger seat by signals from software sensor.

In Table 2 are presented the results of the classification using the combined signal of the three sensors.

A research is done on the work of developed software sensor in case of interruption of one of the input signals.

In Figure 5 are presented output signals from the software sensor using data from the two sensors - temperature and PIR. There is less identifiability of signals compared to variants using combined data from three sensors.

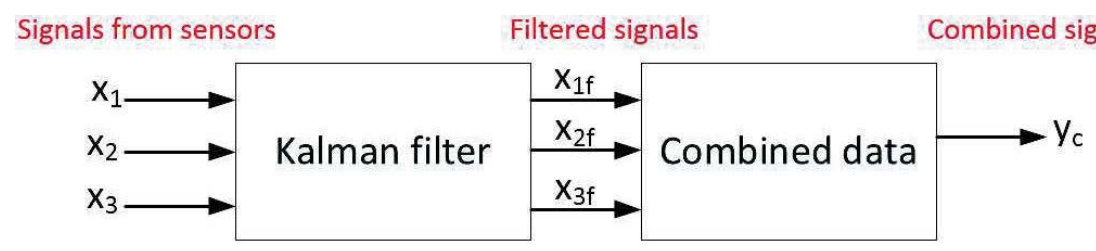

Figure 2: Block diagram of a software sensor.

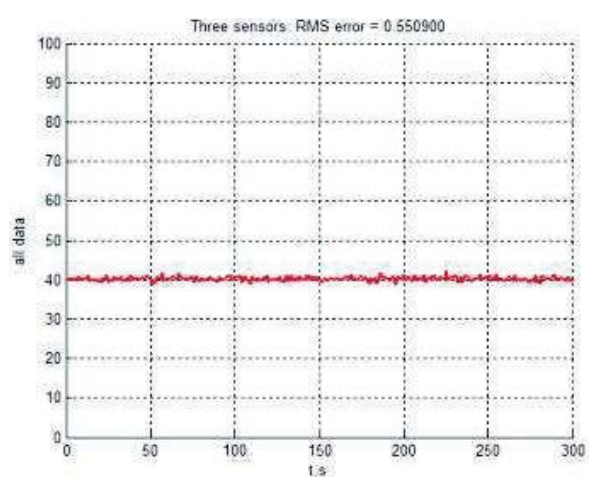

Empty seat

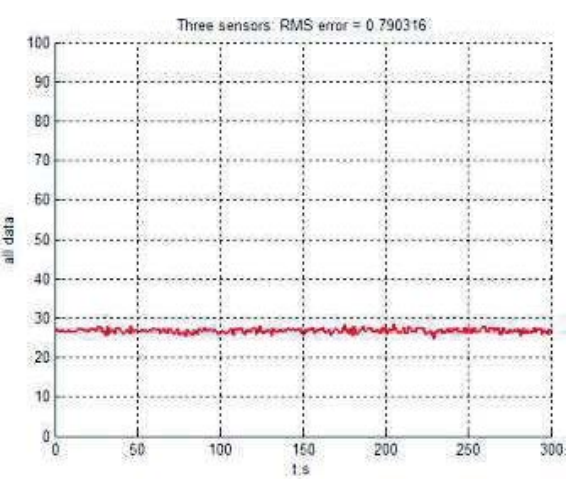

2 years old child

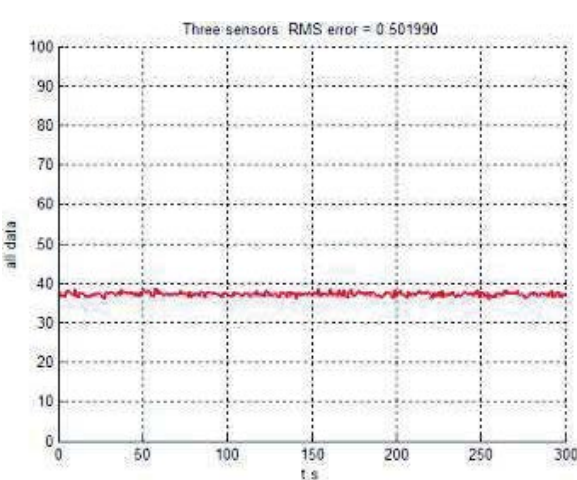

Dog laying

Figure 3: Examples of signals from the sensor software.
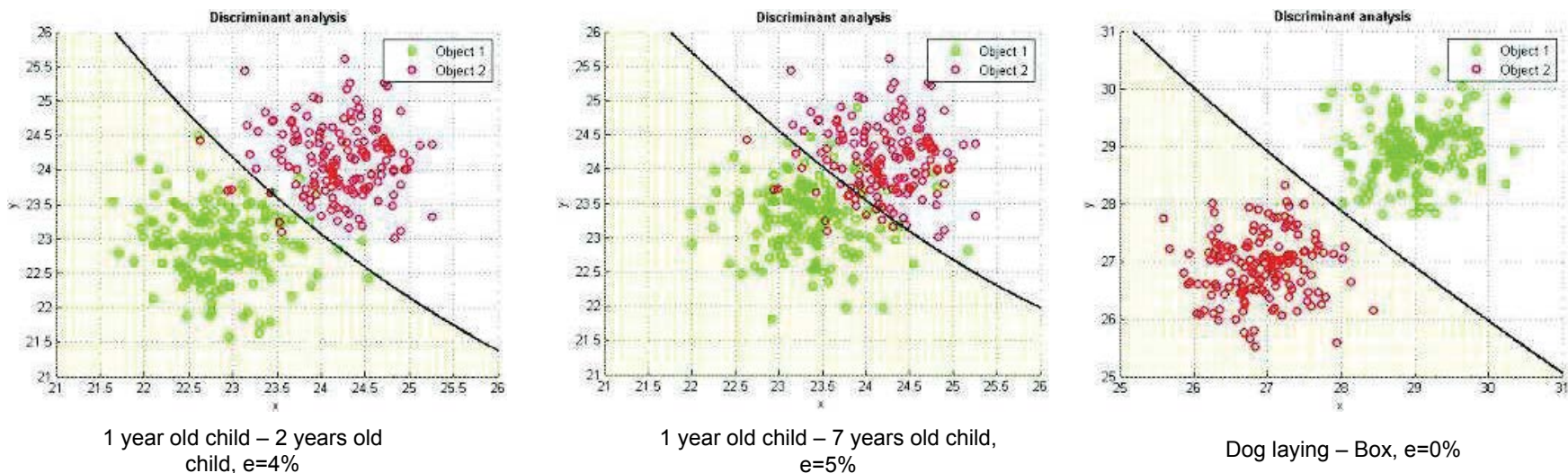

Figure 4: Examples of distinguishing the signals from the sensor software. 
Citation: EINashar EA, Zlatev Z (2018) Analysis of Data from Software Sensor for Smart Airbags Deployment. Adv Robot Autom 7: 181. doi: 10.4172/2168-9695.1000181

Page 4 of 6

In Figure 6 are examples of Severability between objects on the passenger seat by signals from the software sensor in case of failure of the ultrasonic sensor.

In Table 3 are presented the results of the classification using the combined signal of the two sensors, in case of interruption of the ultrasonic one.

In Figure 7 are presented output signals from the software sensor using data from the two sensors - ultrasonic and PIR. There is less identifiability of the signals compared to the variant using the combined data from the three sensors, but better compared to the use of temperature and PIR sensors.

In Figure 8 are examples of separability between objects on the passenger seat by signals from the software sensor in case of interrupted temperature sensor. Table 4 summarize all of the results in this case.

In Figure 9 are summarized the results of the study. With the "+" are marked ability to separate object with an error of less than $5 \%$, and with “-” results with higher error.

The results show that the separation of objects is able by using the combination of the signals of the three sensors. The greatest impact on the performance of the software sensor has the fall of the ultrasonic sensor (Table 5).

\section{Conclusion}

The presented material considered prerequisites and techniques for the application of sensors to activate the intelligent airbags depending on the position and characteristics of the occupants. The principles

\begin{tabular}{|c|c|c|c|c|c|c|c|c|}
\hline Ages & Empty seat & $\begin{array}{l}1 \text { year old } \\
\text { child }\end{array}$ & $\begin{array}{l}2 \text { years old } \\
\text { child }\end{array}$ & $\begin{array}{l}7 \text { years old } \\
\text { child }\end{array}$ & $\begin{array}{l}13 \text { years old } \\
\text { child }\end{array}$ & $\begin{array}{l}22 \text { years old } \\
\text { man }\end{array}$ & Box & Dog laying \\
\hline Empty seat & $x$ & $0 \%$ & $0 \%$ & $0 \%$ & $0 \%$ & $0 \%$ & $0 \%$ & $0 \%$ \\
\hline 1 year old child & $0 \%$ & $x$ & $4 \%$ & $5 \%$ & $0 \%$ & $0 \%$ & $1 \%$ & $0 \%$ \\
\hline 2 years old child & $0 \%$ & $4 \%$ & $x$ & $1 \%$ & $0 \%$ & $0 \%$ & $0 \%$ & $0 \%$ \\
\hline 7 years old child & $0 \%$ & $5 \%$ & $1 \%$ & $x$ & $0 \%$ & $0 \%$ & $0 \%$ & $0 \%$ \\
\hline 13 years old child & $0 \%$ & $0 \%$ & $0 \%$ & $0 \%$ & $x$ & $0 \%$ & $1 \%$ & $0 \%$ \\
\hline 22 years old man & $0 \%$ & $0 \%$ & $0 \%$ & $0 \%$ & $0 \%$ & $x$ & $0 \%$ & $0 \%$ \\
\hline Box & $0 \%$ & $1 \%$ & $0 \%$ & $0 \%$ & $1 \%$ & $0 \%$ & $x$ & $0 \%$ \\
\hline Dog laying & $0 \%$ & $0 \%$ & $0 \%$ & $0 \%$ & $0 \%$ & $0 \%$ & $0 \%$ & $x$ \\
\hline
\end{tabular}

Table 2: Results of classification using the combined signal of the three sensors.

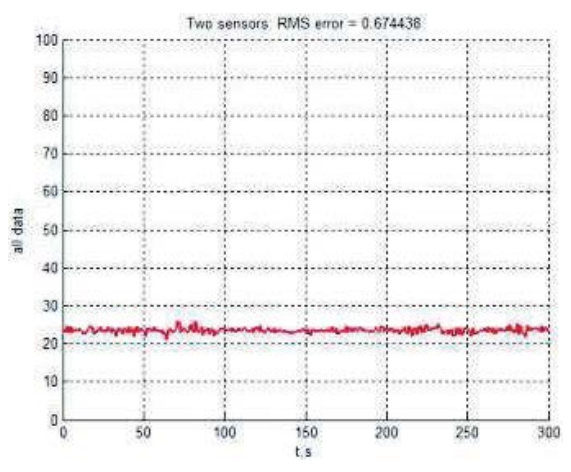

Empty seat

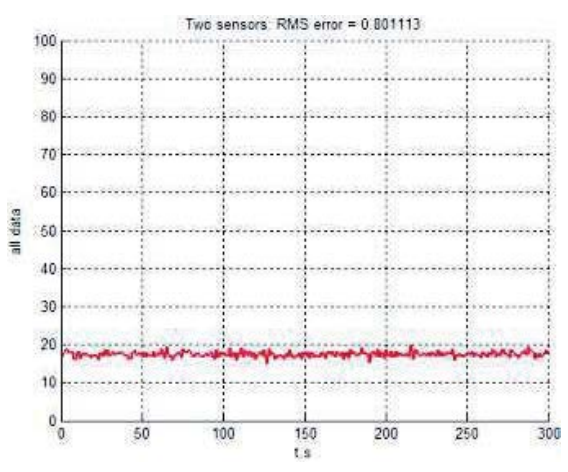

2 years old child

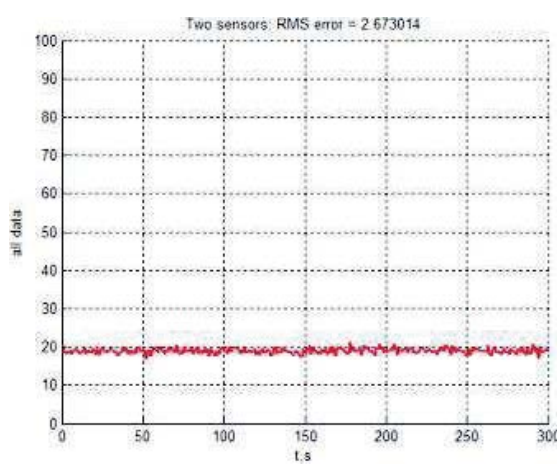

Dog laying

Figure 5: Examples of signals from the software sensor in case of interruption of an ultrasonic sensor.

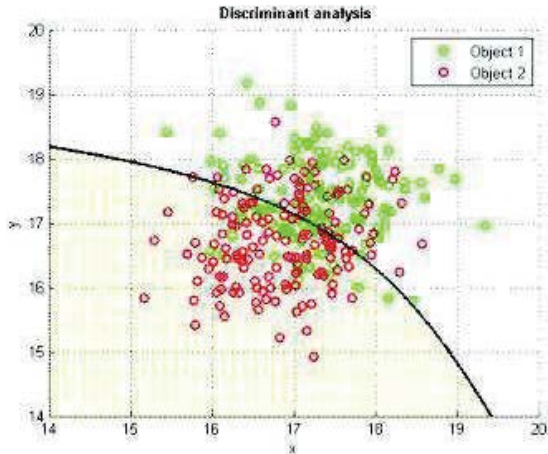

1 year old child -2 years old child, $\mathrm{e}=28 \%$

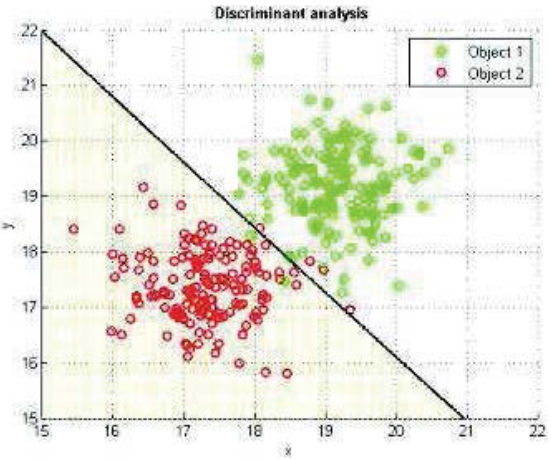

2 year old child -7 years old child, $\mathrm{e}=2 \%$

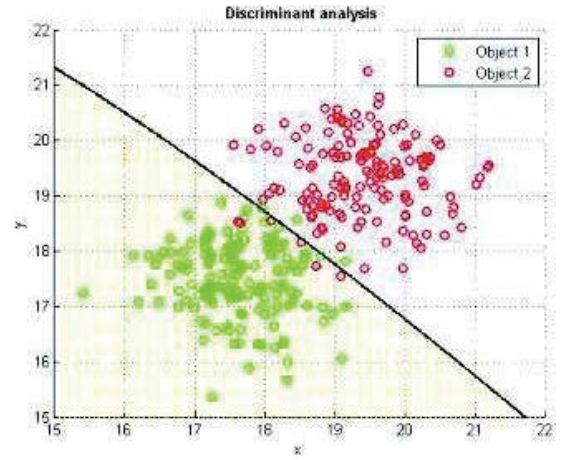

Dog laying - Box, e=3\%

Figure 6: Examples of differentiation of signals from the software sensor in case of interrupted ultrasonic sensor. 
Citation: EINashar EA, Zlatev Z (2018) Analysis of Data from Software Sensor for Smart Airbags Deployment. Adv Robot Autom 7: 181. doi: $10.4172 / 2168-9695.1000181$

Page 5 of 6

\begin{tabular}{|c|c|c|c|c|c|c|c|c|}
\hline Ages & Empty seat & 1 year old child & 2 years old child & 7 years old child & 13 years old child & 22 years old man & Box & Dog laying \\
\hline Empty seat & $x$ & $0 \%$ & $0 \%$ & $0 \%$ & $0 \%$ & $0 \%$ & $0 \%$ & $0 \%$ \\
\hline 1 year old child & $0 \%$ & $\mathrm{x}$ & $28 \%$ & $1 \%$ & $23 \%$ & $2 \%$ & $22 \%$ & $0 \%$ \\
\hline 2 years old child & $0 \%$ & $28 \%$ & $x$ & $2 \%$ & $5 \%$ & $0 \%$ & $41 \%$ & $2 \%$ \\
\hline 7 years old child & $0 \%$ & $1 \%$ & $2 \%$ & $x$ & $0 \%$ & $0 \%$ & $3 \%$ & $36 \%$ \\
\hline 13 years old child & $0 \%$ & $23 \%$ & $5 \%$ & $0 \%$ & $x$ & $10 \%$ & $3 \%$ & $0 \%$ \\
\hline 22 years old man & $0 \%$ & $2 \%$ & $0 \%$ & $0 \%$ & $10 \%$ & $x$ & $1 \%$ & $0 \%$ \\
\hline Box & $0 \%$ & $22 \%$ & $41 \%$ & $3 \%$ & $3 \%$ & $1 \%$ & $x$ & $3 \%$ \\
\hline Dog laying & $0 \%$ & $0 \%$ & $2 \%$ & $36 \%$ & $0 \%$ & $0 \%$ & $3 \%$ & $x$ \\
\hline
\end{tabular}

Table 3: Results for identifiability of objects in case of interrupted ultrasonic sensor.

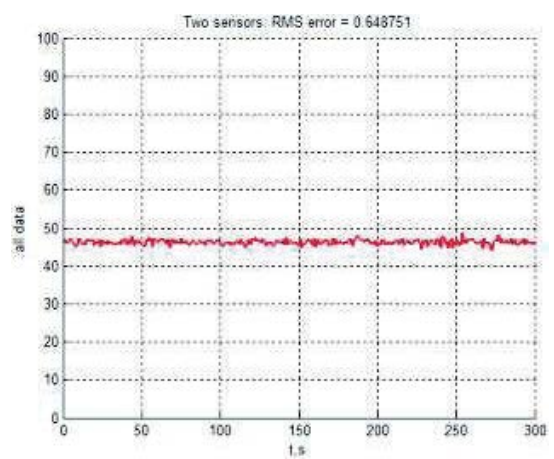

Empty seat

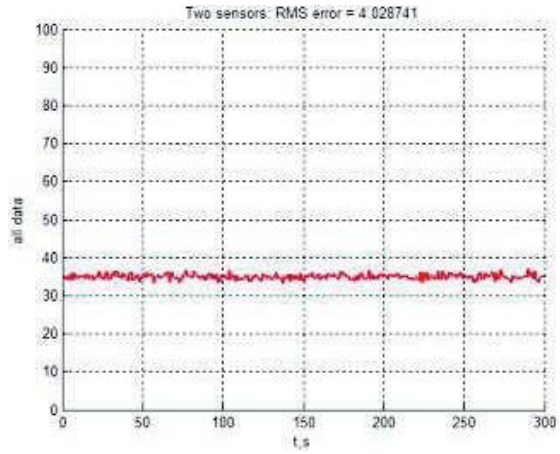

2 years old child

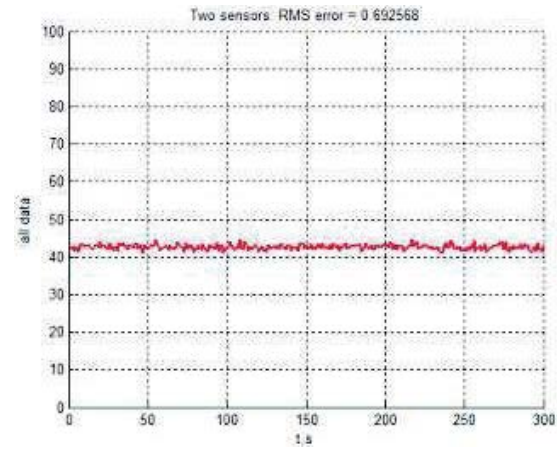

Dog laying

Figure 7: Examples of signals from the software sensor in case of interrupted temperature sensor.

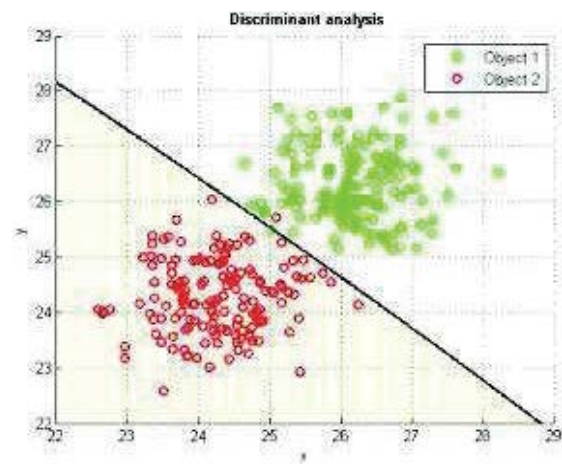

1 year old child -2 years old child, $e=1 \%$

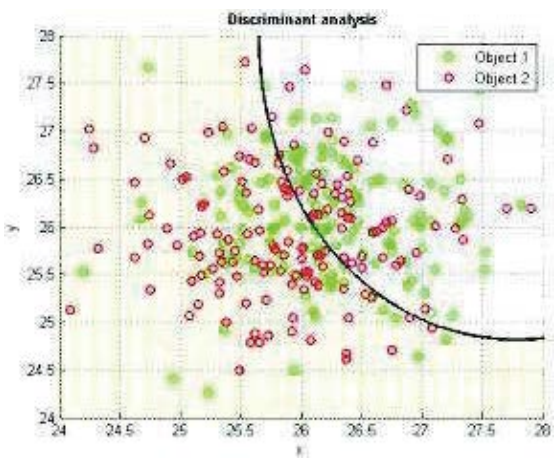

7 year old child -22 years old man, $\mathrm{e}=38 \%$

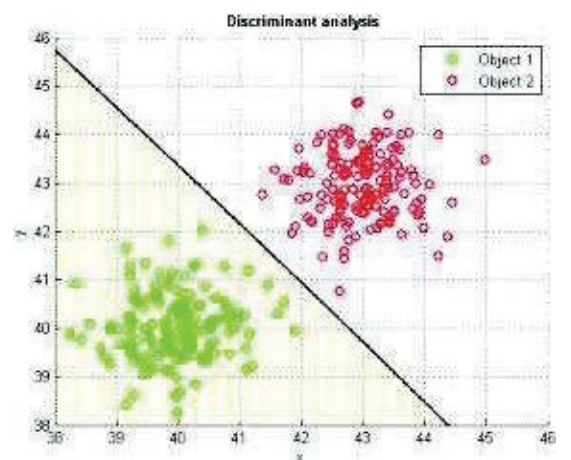

Dog laying - Box, e=0\%

Figure 8: Examples of differentiation of signals from the software sensor in case of interrupted temperature sensor.

\begin{tabular}{|c|c|c|c|c|c|c|c|c|}
\hline Ages & Empty seat & 1 year old child & 2 years old child & 7 years old child & 13 years old child & 22 years old man & Box & Dog laying \\
\hline Empty seat & $\mathrm{x}$ & $0 \%$ & $0 \%$ & $0 \%$ & $0 \%$ & $0 \%$ & $0 \%$ & $7 \%$ \\
\hline 1 year old child & $0 \%$ & $x$ & $1 \%$ & $4 \%$ & $0 \%$ & $2 \%$ & $0 \%$ & $0 \%$ \\
\hline 2 years old child & $0 \%$ & $1 \%$ & $\mathrm{x}$ & $0 \%$ & $0 \%$ & $0 \%$ & $0 \%$ & $0 \%$ \\
\hline 7 years old child & $0 \%$ & $4 \%$ & $0 \%$ & $x$ & $0 \%$ & $38 \%$ & $0 \%$ & $0 \%$ \\
\hline 13 years old child & $0 \%$ & $0 \%$ & $0 \%$ & $0 \%$ & $x$ & $0 \%$ & $39 \%$ & $0 \%$ \\
\hline 22 years old man & $0 \%$ & $2 \%$ & $0 \%$ & $38 \%$ & $0 \%$ & $x$ & $0 \%$ & $0 \%$ \\
\hline Box & $0 \%$ & $0 \%$ & $0 \%$ & $0 \%$ & $39 \%$ & $0 \%$ & $x$ & $0 \%$ \\
\hline Dog laying & $7 \%$ & $0 \%$ & $0 \%$ & $0 \%$ & $0 \%$ & $0 \%$ & $0 \%$ & $x$ \\
\hline
\end{tabular}

Table 4: Results for identifiability of objects in case of interrupted temperature sensor.

of operation and characteristics of sensors is systematically presented and their diversity, described are their advantages and disadvantages.
Presented are software applications using the capabilities of the hardware of sensor devices in order to build a common signal. The 


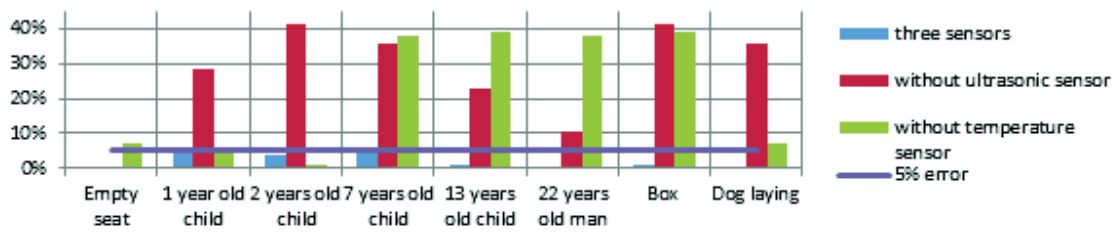

Figure 9: Summary analysis of the research results of a software sensor.

\begin{tabular}{|c|c|c|c|c|c|c|c|c|}
\hline Ages & Empty seat & 1 year old child & 2 years old child & 7 years old child & 13 years old child & 22 years old man & Box & Dog laying \\
\hline Three sensors & + & + & + & + & + & + & + & + \\
\hline $\begin{array}{l}\text { Without ultrasonic } \\
\text { sensor }\end{array}$ & + & - & - & - & - & - & - & - \\
\hline $\begin{array}{l}\text { Without temperature } \\
\text { sensor }\end{array}$ & - & + & + & - & - & - & - & - \\
\hline
\end{tabular}

Table 5: Summary analysis of the research results of a software sensor.

results presented illustrate the advantages and disadvantages of using a software sensor in case of failing of any of the signals transmitted to its input.

From the analysis of the results it is established that:

$>$ By combining data from three hardware sensors is received error up to $5 \%$ in distinguishing between the objects on the passenger seat of the car;

$>$ Dropping of the signal in the hardware sensors affects the accuracy of identifying the object on the passenger seat;

$>$ The higher impact on the performance of the software sensor has the dropping of the signal from the ultrasonic sensor.

\section{References}

1. Mattutat VW (2000) Automotive Handbook, BOSCH (5th edn)

2. Satza A, Hammerschmidtb D, Tumpolda D (2009) Capacitive passenge detection utilizing dielectric dispersion in human tissues, Sensors and Actuators A: Physical 152: 1-4.

3. Adsul R, Joshi S (2013) Performance Modeling of Automotive Sensors and Sensor Interface Systems using Simulink. International Journal of Science and Research (IJSR) 2: 233-243.

4. Schreibera D, Luob $Y$ (2007) Seat detection in a car for a smart airbag application, Pattern Recognition Letters 28: 534-544.

5. Cunningham K, Brown T, Gradwell E, Nee P (1999) Airbag associated fatal head injury: case report and review of the literature on airbag injuries, Airbag associated fatal head injury. J Accid Emerg Med 17: 139-142

6. Dineva P, Kazlacheva Z (2015) Design of women wear with three-dimensional elements, XXIV International scientific conference "Management and quality" for young scientists.

7. Kazlacheva Z, llieva J (2014) History of the costume and fashion.
8. Bailly K, Milgram M (2009) Boosting feature selection for Neural Network based regression, Neural Networks 22: 748-756

9. Boverie S, Devy M, Lerasle F (2003) Comparison of structured light and stereovision sensors for new airbag generations, Control Engineering Practice 11: $1413-1421$

10. Dimitrova A (2016) Analysis of SEM images of magnetically threated ceramic materials. Applied Scientific Journal Innovation and Entrepreneurship 4: 35-43

11. Georgieva K, Georgieva TS, Kirilova E, Daskalov P (2015) Classification of healthy and diseased vine leaves using color features, ARTTE 3: 296-302

12. Mladenov M, Penchev S, Deyanov M (2015) Complex assessment of food products quality using analysis of visual images, spectrophotometric and hyperspectral characteristics. International Journal of Engineering and Innovative Technology (IJEIT) 4: 23-32

13. Kee RS (2014) Detection Systems for Airbag Deployment, Honors Program Projects, p: 49

14. Ivanov M (2015) Specifics of the work of sensors and service for location in Android OS, Working Paper, Scientific electronic archive of the NBU, Sofia.

15. The Extended Kalman Filter: An Interactive Tutorial for Non-Experts.

16. Wikipedia, Central limit theorem.

17. Einicke G (2012) Smoothing, Filtering and Prediction: Estimating the Past, Present and Future. Rijeka, Croatia: Intech.

18. Maybeck S (1982) Stochastic Models, Estimating and Control. River Edge, NJ: Academic Press, p: 291

19. Shivacheva G, Nedeva V, Yaneva M, Georgieva D (2015) Software for building virtual laboratories. XXIV International scientific conference "Management and quality" for young scientists, pp: 292-300.

20. Stoykova $V(2015)$ Interactive environments for training in the higher education International Conference on e-Learning, e-Learning'15, Berlin, pp: 268-273.

21. Tasev G, Krastev K (2011) Exploration of mathematical model for optimization of frequency of diagnosis of the elements of machines, Proceedings of The 11 th International Conference, Reliability and statistics in transportation and communication, Latvia, pp: 115-119. 